\title{
A citometria de fluxo como instrumento de avaliação da atividade imunomodulatória de extratos e substâncias isoladas de plantas medicinais
}

\author{
Julio C. Machado Junior', Angela Florão' ${ }^{1}$, Fernanda V.R. Mattana ${ }^{2}$, Fabiana H. Rocha ${ }^{2}$, \\ Cid A.M. Santos ${ }^{1,3}$, Almeriane M. Weffort-Santos ${ }^{1,2 *}$ \\ 'Programa de Pós-graduação em Ciências Farmacêuticas, Universidade Federal do Paraná, Av. Prefeito Lothário \\ Meissner 632, 80210-170, Jd. Botânico, Curitiba, PR, Brasil, \\ ${ }^{2}$ Departamento de Patologia Médica, Universidade Federal do Paraná, Av. Prefeito Lothário Meissner 632, \\ 80210-170, Jd. Botânico, Curitiba, PR, Brasil, \\ ${ }^{3}$ Departamento de Farmácia, Universidade Federal do Paraná, Av. Prefeito Lothário Meissner 632, 80210-170, Jd. \\ Botânico, Curitiba, PR, Brasil
}

\begin{abstract}
RESUMO: A citometria de fluxo vem se consolidando como metodologia para vários estudos de atividade celular e, nesse trabalho, ela foi empregada para avaliar as ações da fitohemaglutinina, dos alcalóides vimblastina e vindolina e dos extratos de Chamomilla recutita (L.) Rauschert, Bauhinia microstachya (Raddi) Machr. e Himatanthus lancifolius (Muell. Arg.) Woodson, conhecidos popularmente no Brasil como camomila, escada-de-macaco e agoniada, respectivamente, sobre a imunomodulação de células mononucleares humanas, comparando-se o desempenho obtido com as alterações morfológicas relacionadas à ativação e proliferação dessas células in vitro. Os resultados demonstram que foi possível identificar, pela metodologia proposta, os efeitos proliferativos estimulantes já descritos para a fitohemaglutinina e para o extrato de $C$. recutita, assim como para o extrato de $B$. microstachya, observado pela primeira vez nesse trabalho. A conhecida atividade inibitória da vimblastina sobre a proliferação de linfócitos induzida por fitohemaglutinina, em contraste como a ausência de efeitos da vindolina, também puderam ser evidenciadas. Efeito inibitório foi observado para o extrato de H. lancifolius devido à sua ação tóxica sobre o sistema. Os resultados apresentados sugerem que a citometria de fluxo pode ser usada como uma alternativa metodológica quando se deseja investigar a ação de substâncias puras ou de extratos de plantas sobre a imunomodulação de células mononucleares humanas.
\end{abstract}

Unitermos: Citometria de fluxo, imunomodulação, plantas medicinais, alcalóides indólicos, Chamomilla recutita, Bauhinia microstachya, Himatanthus lancifolius.

\begin{abstract}
Flow cytometry as instrument for evaluating the immunopotential of medicinal plant extracts and their isolated compounds". Flow cytometry has been widely applied for studying several cellular activities. In this work it has been used to evaluate the effects of phytohemagglutinin, vinblastine, and vindoline upon human mononuclear cells immunomodulation. The same protocol was used to investigate the effects of extracts prepared from Chamomilla recutita (L.) Rauschert, Bauhinia microstachya (Raddi) Machr., and Himatanthus lancifolius (Muell. Arg.) Woodson, plants popularly known in Brazil as camomila, escada-de-macaco, and agoniada, respectively. The activity was then compared with the in vitro cellular morphological changes. By the results herein presented, the proposed method allowed the identification of the already known phytohemagglutinin and C. recutita extract proliferative effects, as well as for the B. microstachya extract, reported for the first time. The inhibition of vinblastine upon the proliferation of phytohemagglutin-stimulated cells and the lack of effects of vindoline were also evident. Exposition to $H$. lancifolius extract has led to inhibition of lymphocyte proliferation as a result of the high toxicity of the extract upon the system. Results presented strongly suggest flow cytometry as a useful instrument to evaluate the immunomodulation effects of pure compounds or complex mixtures such as plant extracts upon human mononuclear cells.
\end{abstract}

Keywords: Flow cytometry, immunomodulation, medicinal plants, indol alkaloids, Chamomilla recutita, Bauhinia microstachya, Himatanthus lancifolius. 


\section{INTRODUÇÃO}

Uma diversidade de atividades biológicas apresentadas por plantas usadas na medicina caseira e de substâncias delas extraídas e purificadas vem sendo demonstrada por meio de modelos experimentais in vivo e in vitro e o espectro dessas ações amplifica na mesma proporção que metodologias mais específicas vão se consolidando cientificamente (Funke; Melzig, 2006; Leitão et al., 2006; Barbosa-Filho et al., 2006). De particular interesse são aquelas direcionadas ao estudo das atividades imunomodulatórias, devido ao crescente número de espécies vegetais utilizadas para o tratamento de doenças que comprometem o sistema imunitário (Yamaguchi, 1992; Lopes et al., 2003; Carlos et al., 2005; Bezerra-Santos et al., 2005), especialmente aquelas associadas ao câncer (Hirazumi et al., 1996) e às doenças infecciosas crônicas (Zarkovic et al., 2001).

Várias são as metodologias atualmente empregadas para quantificar a ativação e a proliferação celulares in vitro. Dentre elas, despontam aquelas em que há a incorporação de nucleotídeos radioativos ao DNA celular durante a replicação e a resposta proliferativa é determinada pelos níveis de radiomarcador presente nas distintas populações celulares. Nesse contexto, destacase o uso da timidina tritiada (Brunner et al., 1968, Gillis et al., 1978).

Elevadas sensibilidade e reprodutibilidade caracterizam as vantagens desses métodos, porém muitas são as desvantagens. Dentre essas, destacase a manipulação de componentes radioativos, a qual requer precauções especiais de segurança, como salas e equipamentos exclusivos, além de proteção e treinamento pessoal especializado; sendo uma metodologia que envolve várias etapas de trabalho detalhado e minucioso, as chances de erro e contaminação se ampliam, além do custo consumido para cada série de experimentos. A redução de sais tetrazólio, como o MTT (brometo de 3-[4,5-dimetiltiazolil]-2,5-difeniltetrazólio) e outros derivados, por redutases (Mosmann, 1983) constitui-se de metodologia alternativa, porém ambas metodologias não permitem estudos subseqüentes com as células, uma vez que comprometem sua viabilidade.

A citometria de fluxo (CF) surge, então, como uma instrumentação alternativa importante para o estudo dos eventos celulares envolvidos na resposta imunológica com aplicações clínicas subseqüentes (Macey, 1994), porque uma das características deste instrumento é a manutenção das condições vitais da célula após sua manipulação, permitindo investigações mais aprofundadas do comportamento biológico da população em estudo, inclusive de avaliação funcional.

Essa versatilidade metodológica deriva da múltipla e independente quantidade de análises das características físicas e químicas das células (Shapiro, 1985), pois no citômetro elas são individualmente conduzidas em canal de corrente fluida que, ao interceptarem o feixe de luz geralmente proveniente de um laser, causam sua dispersão em várias direções, dependendo do tamanho, da estrutura interna, das características topográficas e de densidade óptica de cada célula (Macey, 1994), as quais estão diretamente correlacionadas com a morfologia celular que pode ser apreciada em preparados corados. Nesse contexto, o feixe de luz que passa pela partícula com um mínimo de desvio está relacionado com o tamanho celular (forward light scatter - FSC), enquanto aqueles que captam o desvio ortogonal aos eixos do fluído celular e do laser (side light scatter - SSC) estão relacionados com a complexidade celular interna, em particular sua granularidade (Macey, 1994, Robinson, 1993, Shapiro, 1985). Após análise simultânea desses parâmetros, gráficos de coordenadas $x$ e $y$ são, então, gerados (Macey, 1994).

Uma vez que a fitohemaglutinina (PHA), lectina de Phaseolus vulgaris, é dotada das propriedades de ativar e induzir a proliferação de linfócitos humanos in vitro (Nowell, 1960), no presente trabalho empregou-se a CF como instrumento alternativo para avaliar essas atividades e compará-las às alterações morfológicas que descrevem essas atividades. Da mesma forma, avaliou-se o comportamento de células mononucleares na presença de vimblastina, alcalóide extraído de Catharantus roseus reconhecidamente inibidor da proliferação de linfócitos induzida por PHA (Thyberg et al., 1977), e de vindolina, outro alcalóide também extraído desta planta, mas sem estudos similares. Explorou-se, ainda, a influência, sobre a proliferação de células mononucleares humanas, dos extratos hidroetanólicos preparados de capítulos florais de Chamomilla recutita (L.) Rauschert, Asteraceae, de folhas de Bauhinia microstachya (Raddi) Machr., Leguminosae, e de cascas de Himatanthus lancifolius (Muell. Arg.) Woodson, Apocynaceae, popularmente conhecidas como camomila, escada-de-macaco e agoniada e amplamente utilizadas na medicina tradicional (Duarte; Debur et al., 2003; Pereira et al., 2004; Tôrres et al., 2005).

\section{MATERIAL E MÉTODOS}

\section{Material botânico}

Capítulos florais de Chamomilla recutita (L.) Rauschert, Asteraceae, de uma amostra comercial pronta para consumo, de origem egípcia, adquirida em ervanário da região central de Curitiba, Brasil, foram caracterizados por análise farmacognóstica conforme a Farmacopéia Brasileira $4^{a}$ ed. (1996) e por análise em CG/EM dos constituintes do óleo essencial, extraído com auxílio de aparelho de Clevenger. Folhas de Bauhinia microstachya (Raddi) Machr., Leguminosae, foram coletadas na região de Morretes, Paraná, e uma exemplar encontra-se depositado no Herbário do Museu Botânico de Curitiba, sob registro 264.361. Cascas de Himatanthus lancifolius (Müll.) Argov, Apocynaceae, foram adquiridas na região metropolitana de São Paulo, Brasil, e identificadas 
conforme descrição da Farmacopéia Brasileira $1^{\text {a }}$ ed. (1929) e por comparações macro e microscópicas com amostras autênticas. Uma amostra de cada planta encontra-se depositada na Herboteca do Laboratório de Farmacognosia, Departamento de Farmácia, Universidade Federal do Paraná.

\section{Preparação dos extratos}

Material botânico seco pulverizado (50 g) foi macerado em etanol 20\% (200 mL) por $48 \mathrm{~h}$. Após serem filtrados em malha de gaze com algodão para retirada de material particulado, os extratos foram levados à secura por evaporação em banho-maria $45-55^{\circ} \mathrm{C}$. Em seguida, foram liofilizados e mantidos a $-20^{\circ} \mathrm{C}$ até serem utilizados. Soluções a $10 \%(\mathrm{p} / \mathrm{v})$ foram preparadas em RPMI 1640 (Gibco) no momento do uso, esterilizadas por filtração $(0,22 \mu \mathrm{m}$ - Acrodisc $)$ e incorporadas nos experimentos.

\section{Alcalóides}

Foram usadas ampolas de sulfato de vimblastina, do Laboratório Foulding Farmacêutica do Brasil Ltda, registro 1.3139.0015, no Ministério da Saúde, e vindolina, em pó, produzida pelo Laboratório Eli Lilly \& Co., Indianápolis, U.S.A., registro 801-891B-128A no Ministério da Saúde. Ambos alcalóides foram ensaiados nas concentrações de $10^{-3}$ a $10^{-10} \mathrm{M}$. As soluções desses alcalóides foram preparadas em RPMI 1640 e esterilizadas por filtração no momento do uso.

\section{Obtenção de leucócitos e isolamento de células mononucleares}

Dez a vinte mililitros de sangue venoso heparinizado, colhidos assepticamente de voluntários sem manifestação de sinais ou sintomas de doença e sem uso de medicamentos, foram utilizados como fonte de células mononucleares (MNC), após consentimento livre e esclarecido, aprovado pelo Comitê de Ética em Pesquisas em Seres Humanos do Hospital de Clínicas da Universidade Federal do Paraná, sob Protocolo CEP/HC 10, EXT.059/2003-10. As amostras foram centrifugadas a $800 \mathrm{~g}$ por $25 \mathrm{~min}$ em temperatura ambiente; o creme leucocitário foi removido e re-suspenso em $12 \mathrm{~mL}$ de salina tamponada com fosfatos (PBS; $\mathrm{NaH}_{2} \mathrm{PO}_{4} \cdot 2 \mathrm{H}_{2} \mathrm{O}$ $150 \mathrm{mM} ; \mathrm{Na}_{2} \mathrm{HPO}_{4} 150 \mathrm{mM}$; $\mathrm{NaCl} 154 \mathrm{mM}$; pH 7,4). Após homogeneização, a suspensão celular foi transferida para tubo de centrífuga contendo $3 \mathrm{~mL}$ de Ficoll-Paque ${ }^{\mathrm{TM}}$ PLUS (Amersham, Biosciences) e centrifugada a 200 $g$ por $30 \mathrm{~min}$. MNC retidas na interface das soluções foram removidas, lavadas duas vezes em PBS ( $400 \mathrm{~g}$ por $10 \mathrm{~min})$ e re-suspensas em RPMI 1640 suplementado com $10 \%$ (v/v) de uma mistura de soros humanos. Depois de enumeradas com auxílio de hemocitômetro, a concentração celular foi ajustada para $10^{6}$ células $/ \mathrm{mL}$.

\section{Testes de viabilidade e toxidade}

MNC foram diluídas em solução de azul de tripano a $0,4 \%(p / v)$ em PBS e sua viabilidade observada ao microscópio óptico, antes e após os procedimentos experimentais. As células discriminadas como viáveis apresentaram-se íntegras, brilhantes, incolores e redondas, enquanto aquelas que se mostravam coradas em azul e com perda da definição de contorno foram consideradas não viáveis. Somente amostras contendo $>95 \%$ de células viáveis foram utilizadas nos experimentos.

\section{Citocentrifugados}

Preparações citológicas foram obtidas após submeter-se $2 \times 10^{4} \mathrm{MNC}$ a $1500 \mathrm{rpm}$ por $5 \mathrm{~min}$, sob baixa aceleração, em citocentrífuga Cytopro ${ }^{\mathrm{TM}}$ (Wescor). Em seguida, as lâminas secas ao ar foram coradas com May-Grünwald-Giemsa. Fotografias foram obtidas usando-se o software IMAGE PRO PLUS acoplado ao microscópio Olympus CH30.

\section{Ativação de linfócitos avaliada morfologicamente (transformação blástica)}

Citocentrifugados corados foram observados sob microscopia de imersão e um mínimo de 100 células/ experimento diferenciado. Foram considerados linfócitos todas as células arredondadas, pequenas, com elevada relação núcleo-citoplasmática, citoplasma escasso, de coloração azul, ausência de granulação específica, núcleo arredondado e denso, com cromatina apresentandose com agregados irregulares e eventual presença de estruturas semelhantes a nucléolos, porém mal definidos. Linfócitos transformados pela ação de fitohemaglutinina foram considerados como blastos e identificados como células de contorno irregular, maiores do que linfócitos não-ativados, citoplasma azul intenso, geralmente vacuolizado, com Complexo de Golgi desenvolvido, definido como área não corada ao redor do núcleo; presença de dois ou mais nucléolos proeminentes e delineados imersos em cromatina nuclear delicada (Lee et al., 1999).

\section{Ativação/proliferação de linfócitos avaliada por citometria de fluxo}

MNC $\left(10^{6}\right.$ células $\left./ \mathrm{ml}\right)$ foram incubadas em RPMI 1640, suplementado com proporções crescentes (5 a 90\%, v/v) de Meio para Cariótipo contendo Fitohemaglutinina (M-PHA; Cultilab-Campinas/SP) e $10 \%$ de uma mistura de soros humanos em placas de 96 poços (TPP - Switzerland), a $37^{\circ} \mathrm{C}$ por 3 a 5 dias, em atmosfera de $5-10 \%$ de $\mathrm{CO}_{2}$. Cada ensaio foi realizado em triplicata e, como resultado de cada experimento, usou-se a média da triplicata. Para avaliar a atividade imunomodulatória, alcalóides $\left(10^{-3}-10^{-10} \mathrm{M}\right)$ e concentrações crescentes

16(Supl.):dez. 2006 
de extratos de plantas medicinais $(0,1-100 \mu \mathrm{g} / \mathrm{mL})$, foram adicionados simultaneamente aos ensaios. Após incubação, as células foram transferidas para tubos de ensaio apropriados e analisados por citometria de fluxo usando-se um instrumento FACSCalibur (Becton \& Dickinson), equipado com laser de Argônio (488 $\mathrm{nm})$. Para avaliação da ativação celular, as análises se basearam na aquisição de $10^{4}$ eventos/ensaio. Para cada análise de proliferação, eventos foram adquiridos por 30 segundos, na velocidade alta, em escala linear. Gráficos baseados no tamanho (FSC) e na complexidade interna (SSC) das células foram construídos usando-se janelas discriminatórias para as populações de linfócitos e blastos. A janela R1 foi delineada, de forma subjetiva, para especificar a população de células cultivada sem aditivos e usada como controle, enquanto R2 foi delineada, também de forma subjetiva, para especificar a população de células cultivadas na presença de fitohemaglutinina, alcalóides ou extratos, e que inclui a população de R1. Os dados foram analisados usando-se o software WinMDI 2.8 e os resultados estão expressos como índice de proliferação (IP), onde a média aritmética das triplicatas (X) dos valores obtidos por ensaio foram aplicadas como a seguir: $\mathrm{IP}=\mathrm{X}$ (células detectadas em $\mathrm{R} 2_{\text {teste }}$ ) / X (células detectadas em R2 ${ }_{\text {controle }}$ ).

\section{Análise estatística}

Os resultados estão apresentados como a média \pm 1 erro padrão da média (EPM). Para análise estatística dos resultados, usou-se o teste $t$ de Student. Os cálculos foram realizados utilizando-se o software OriginPro 6.1 e valores de $\mathrm{P}<0,05$ foram considerados significativos.
Quando necessário, análises foram realizadas para a obtenção do índice de correlação $(r)$ entre dois grupos, usando-se o teste de correlação de Pearson.

\section{RESULTADOS}

\section{Efeitos da concentração de fitohemaglutinina sobre a viabilidade e a ativação de linfócitos avaliada morfologicamente}

Ao avaliar-se a morfologia de MNC do grupo controle em citocentrifugados corados com MayGrunwald-Giemsa preparados após incubação, observouse que, em média, somente $5,8 \pm 1,2 \%$ das células demonstravam morfologia característica de linfoblastos $(\mathrm{n}=6)$, sendo o restante constituído por linfócitos. Em contraste, linfoblastos constituíram 89,6 $\pm 1,2 \%(\mathrm{n}=$ 30; $\mathrm{P}<0,0000)$ das populações estimuladas com PHA. Essa distribuição distinta de linfócitos e linfoblastos nas culturas, cujas morfologias estão ilustradas na Figura 1, foi independente da proporção de meio contendo fitohemaglutinina (M-PHA) e do tempo de incubação.

Com relação à viabilidade das células do grupo controle avaliada com azul de tripano, o número de MNC viáveis decresceu com o aumento do período de incubação (Figura 2). A viabilidade média observada foi de $87,6 \pm 1,3 \%(n=8)$ em culturas de três dias, enquanto que, após quatro e cinco dias de cultivo, declínio significativo foi observado, registrando valores de 73,6 $\pm 3,5 \%(\mathrm{n}=8 ; \mathrm{P}<0,01)$ e $65,0 \pm 4,0 \%(\mathrm{n}=$ $8 ; \mathrm{P}<0,0001)$, respectivamente. Entretanto, quando incubados na presença de concentrações crescentes de M-PHA, após três dias de incubação, a viabilidade média
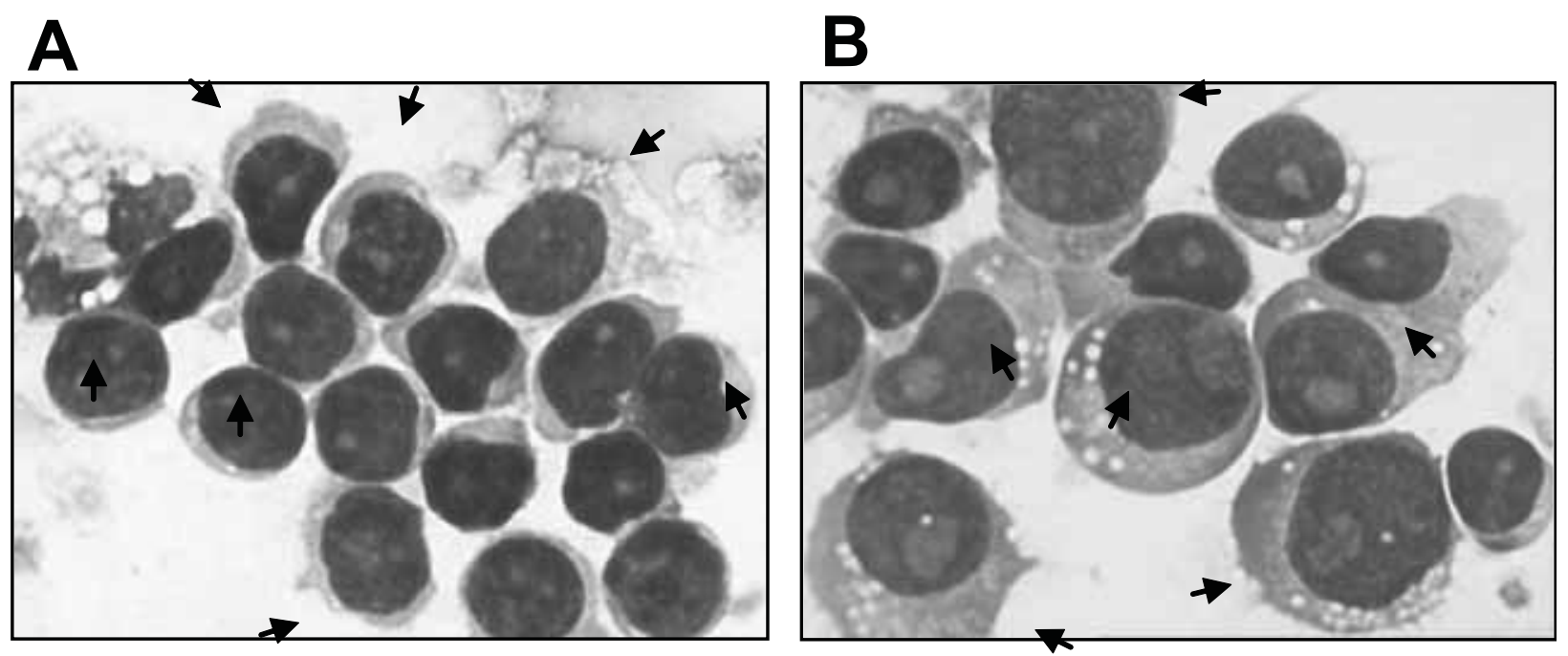

Figura 1. Efeitos da fitohemaglutinina sobre a morfologia de células mononucleares. Células mononucleares obtidas após isolamento com gradiente de densidade foram incubadas por 3 a 5 dias, a $37^{\circ} \mathrm{C}$, em atmosfera de $\mathrm{CO}_{2}$. Em alguns experimentos, meio de cultura contendo fitohemaglutinina foi acrescentado. Linfócitos (A, setas), em detrimento de linfoblastos (B, setas), distintos entre si pela morfologia característica observada em citocentrifugados corados com May-Grünwald-Giemsa, predominaram nas culturas sem o mitógeno (x1000). 


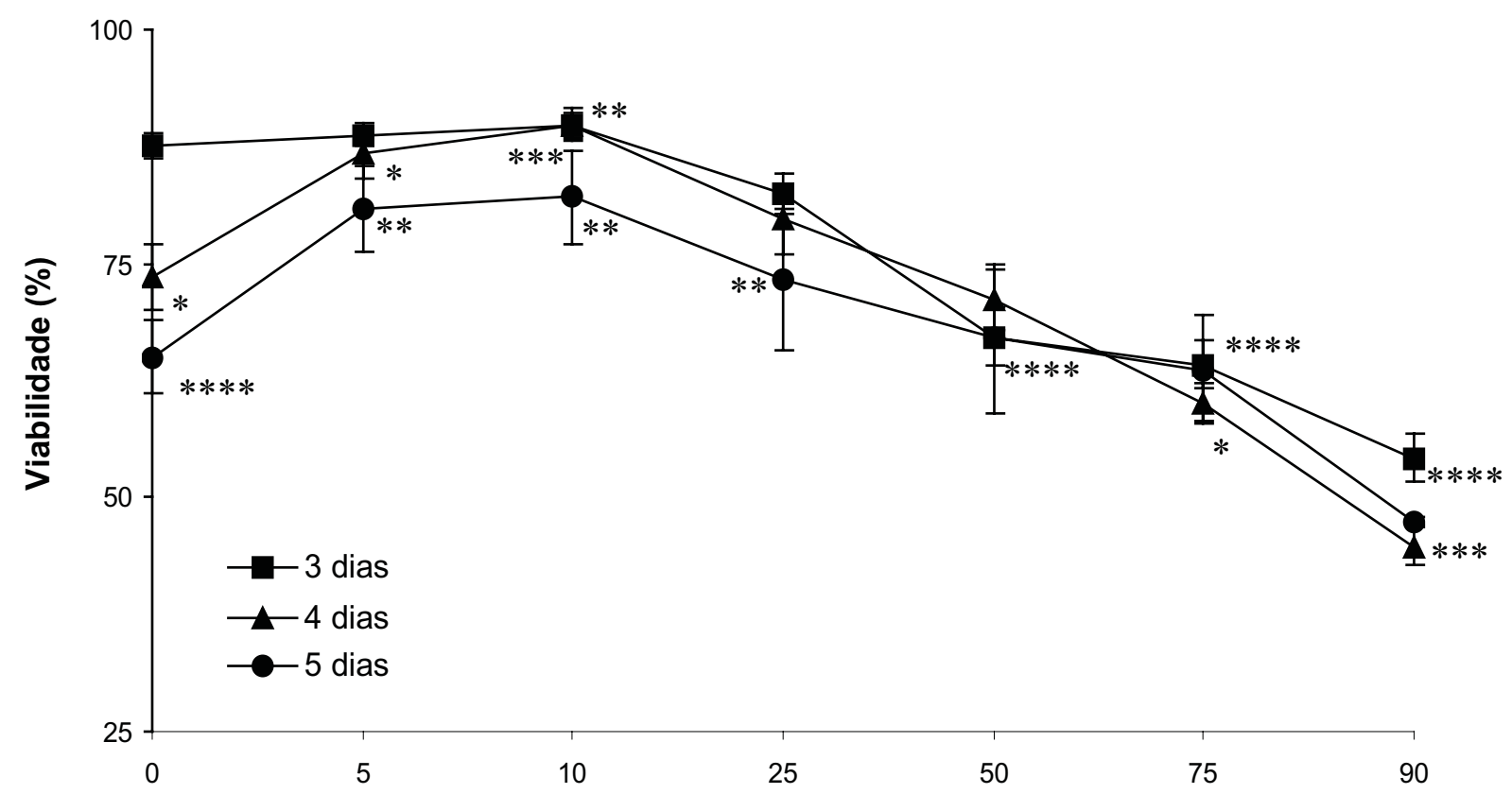

fitohemaglutinina (\%)

Figura 2. Influência da concentração de fitohemaglutinina sobre a viabilidade de células mononucleares in vitro. Células mononucleares obtidas de sangue periférico de voluntários sadios, após isolamento em gradiente de densidade, foram tratadas com proporções crescentes, como indicado, do meio de cultura comercial enriquecido com fitohemaglutinina e incubadas a $37^{\circ} \mathrm{C}$ por 3 a 5 dias, em atmosfera de $\mathrm{CO}_{2}$. Cada linha representa a viabilidade celular média \pm EPM em percentagem, verificada pelo teste com azul de tripano. ${ }^{*} \mathrm{P}<0,01 ; * * \mathrm{P}<0,02 ; * * * \mathrm{P}<0,001 ; * * * * \mathrm{P}<0,0001 \mathrm{em}$ relação ao controle, não estimulado.

das MNC manteve-se superior a $80 \%$ até a concentração de $25 \%$ de meio, quando, então, observou-se um declínio dependente da dose significativo em relação ao controle, com somente $67,1 \pm 3,1,64,3 \pm 2,5 \%$ e $54,3 \pm 3,5 \%$ das células mantendo-se viáveis para as proporções de 50,75 e $90 \%$, respectivamente $(\mathrm{n}=8 ; \mathrm{P}<0,0001$ para todos). O potencial tóxico apresentado pela $\mathrm{PHA}$ em altas concentrações foi mais evidente a partir do quarto dia de incubação, onde viabilidade celular média de $60,1 \pm$ $2,1 \%(\mathrm{n}=8 ; \mathrm{P}<0,01)$ foi registrada na presença de $75 \%$ de M-PHA. Quando se incubou as MNC com $90 \%$ de M-PHA, somente 47,5 $\pm 0,6 \%(n=8 ; P<0,001)$ delas mantiveram-se viáveis. Em contraste, na presença de somente cinco ou $10 \%$ de M-PHA, a viabilidade média observada foi de $86,8 \pm 2,7 \%(\mathrm{n}=8 ; \mathrm{P}<0,01)$ e $89,9 \pm$ $1,7 \%(\mathrm{n}=8 ; \mathrm{P}<0,001)$, respectivamente, após quatro dias de incubação, e de $80,9 \pm 4,5 \%$ e $82,1 \pm 5,0 \%$ (ambos $\mathrm{n}=8 ; \mathrm{P}=0,02)$ após 5 dias, sendo significativamente superiores às concentrações elevadas avaliadas.

Efeitos da concentração de fitohemaglutinina sobre a ativação de linfócitos avaliada por citometria de fluxo

A estratégia utilizada para avaliar a ativação de MNC por CF, ilustrada na Figura 3, baseou-se na

comparação da distribuição das células quando expostas ou não ao mitógeno. Assim, em um gráfico de pontos, linfócitos em estado basal, por serem células relativamente pequenas e de baixa complexidade interna, ocupam uma posição de baixos FSC e SSC (Civin; Loken, 1987). Após um período de incubação, permanecem nessa mesma posição, em contraste com uma população exposta a fitohemaglutinina, a qual promove sua ativação. Como conseqüência, transformam-se em imunoblastos, aumentando de tamanho e em complexidade interna, características provenientes de um estado metabólico intenso. Esse trânsito entre repouso e ativação, também denominado transformação blástica, pode ser evidenciado pela migração das células da região $\mathrm{R} 1$ para $\mathrm{R} 2$, como ilustrado na Figura 3. Nesse contexto, observou-se que $92,6 \pm 4,3 \%$ das $\mathrm{MNC}$ do grupo controle permaneceram em R1 após o período de incubação (Figura 3.A), em contraste com os somente $16,1 \pm 4,9 \%(\mathrm{n}=22$; $\mathrm{P}<0,0001)$ observados para esta região nas culturas estimuladas com mitógeno (Figura 3.B). Ou seja, na presença de fitohemaglutinina, mais de $80 \%$ das células se deslocaram da região R1, se posicionando em uma região de maiores FSC e SSC, indicando que as células sofreram modificações com relação ao tamanho e à complexidade interna, respectivamente, sugerindo que 

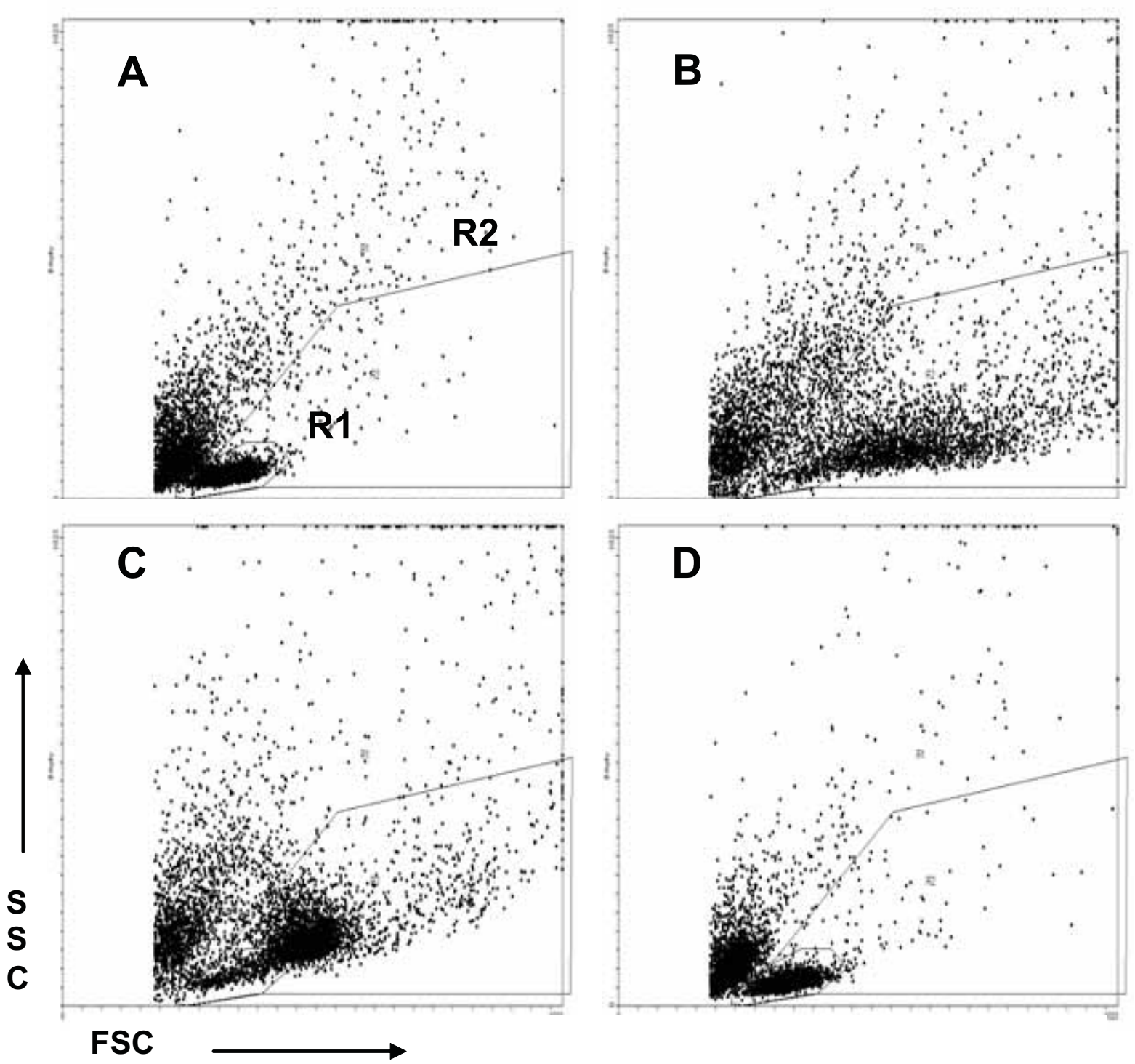

Figura 3. Estratégia para análise dos efeitos da fitohemaglutinina e de alcalóides sobre a ativação/proliferação de células mononucleares por citometria de fluxo. Células mononucleares obtidas de sangue periférico de voluntários sadios foram cultivadas por 5 dias, a $37^{\circ} \mathrm{C} \mathrm{e} \mathrm{em} \mathrm{atmosfera} \mathrm{de} \mathrm{CO}_{2}$ (A). Em alguns experimentos, fitohemaglutinina (B), vimblastina $(\mathbf{C})$ ou vindolina $(\mathbf{D})$, isolados ou em combinação, foram adicionados às culturas. Os gráficos representam as células analisadas por citometria de fluxo, onde as características de tamanho (FSC) e complexidade interna (SSC) foram utilizadas para distinguir cada população e definir as regiões para avaliar a proliferação de linfócitos dos grupos controle e tratados. R1 denota a região delimitada para linfócitos não estimulados, e R2, a região para linfoblastos, onde cada ponto representa uma célula detectada no sistema.

esse deslocamento está relacionado à ativação celular e corroborando com observações descritas por outros (Gaines et al., 1996). Além disso, esses resultados estão de acordo com a análise citológica dessas duas populações descritas no item anterior. De fato, ao se relacionar os dados obtidos por $\mathrm{CF}$ com as análises citomorfológicas, um índice de correlação de $r=0,98$ foi obtido, indicando que os eventos detectados na região R2 dos gráficos FSC x SSC representam linfócitos que foram ativados pela ação da PHA, sofreram transformação blástica e deram origem a linfoblastos funcionais.

Efeitos da concentração de fitohemaglutinina sobre a proliferação de linfócitos avaliada por citometria de fluxo

Após ter-se constatado o potencial ativador da PHA em baixas concentrações sobre a população de MNC, tanto morfologicamente quanto por $\mathrm{CF}$, investigou-se os efeitos de diferentes concentrações de M-PHA sobre 


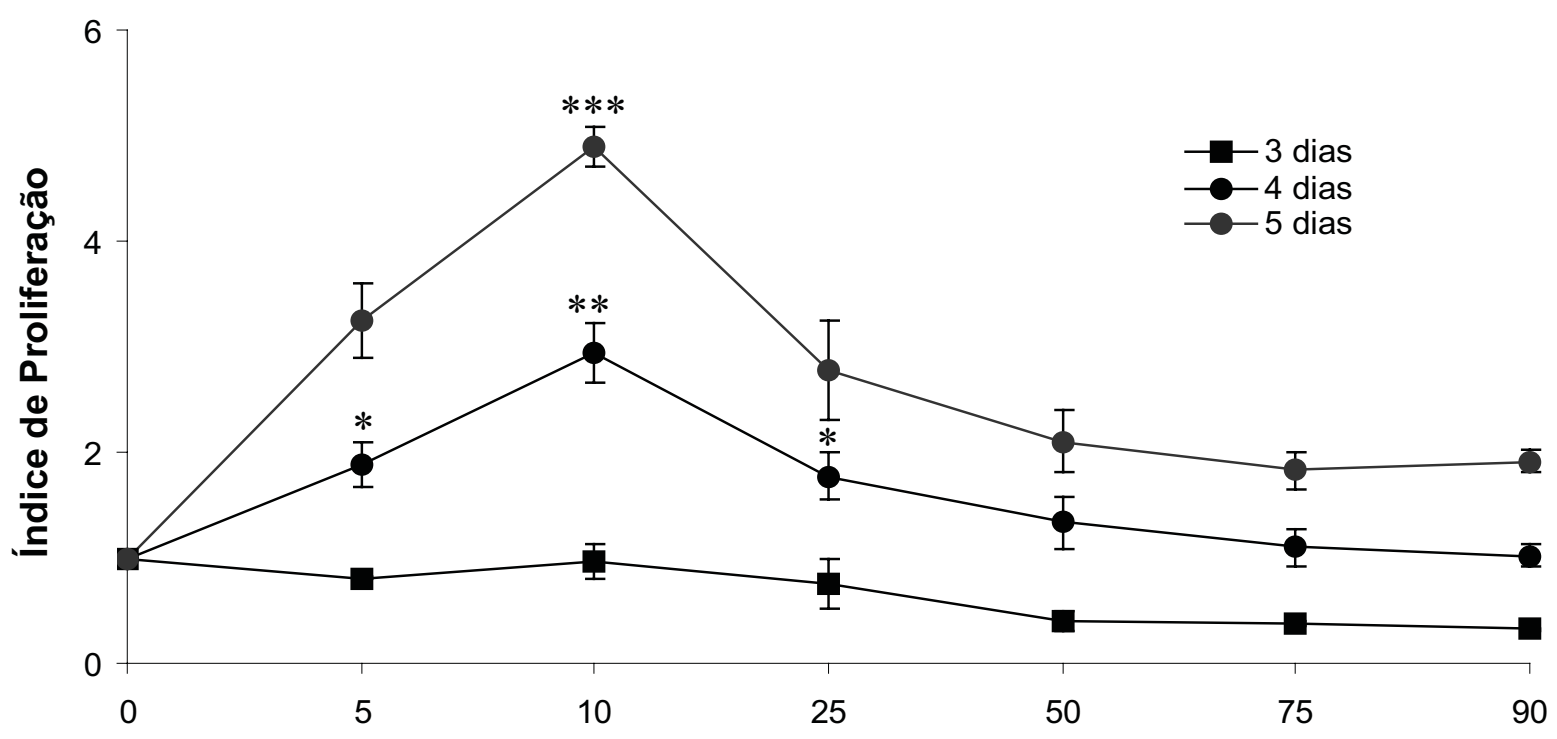

fitohemaglutinina (\%)

Figura 4. Efeito da concentração da fitohemaglutinina sobre a proliferação de linfócitos humanos. Células mononucleares obtidas de sangue periférico de voluntários sadios, após isolamento em gradiente de densidade, foram tratadas com proporções crescentes do meio de cultura Meio para Cariótipo enriquecido com fitohemaglutinina como indicado e incubadas a $37^{\circ} \mathrm{C}$ por 3 a 5 dias, em atmosfera de $\mathrm{CO}_{2}$. Os pontos representam a relação média \pm EPM do número de eventos detectados por citometria de fluxo entre as culturas estimuladas por fitohemaglutinina em relação à fração não estimulada. $* \mathrm{P}<0,01 ; * * \mathrm{P}<0,001 ; * * * \mathrm{P}<0,00001$ em relação ao controle não estimulado.

a proliferação dessa população celular. Como ilustrado na Figura 4, com apenas três dias de incubação, não se observou expansão dessa população em nenhuma das concentrações utilizadas de meio enriquecido com fitohemaglutinina, quando comparado à população controle. Entretanto, esta atividade tornou-se evidente e significativa a partir do quarto dia, nas concentrações de 5,10 e $25 \%$ de M-PHA, com um aumento significativo do número de células presentes na região $\mathrm{R} 2$, com um IP de $1,89 \pm 0,22(\mathrm{n}=4 ; \mathrm{P}<0,01), 2,95 \pm 0,28(\mathrm{n}=$ $5 ; \mathrm{P}<0,001)$ e $1,77 \pm 0,22(\mathrm{n}=5 ; \mathrm{P}<0,01)$ vezes, respectivamente, em relação ao grupo não tratado. Após cinco dias de incubação, todas as concentrações de MPHA avaliadas foram eficientes em estimular a divisão celular, apresentando aumento significativo do número de células em relação ao controle não estimulado. Porém, foi na concentração de $10 \%$ de M-PHA onde se observou o melhor e mais significativo efeito, com um IP de 4,90 $\pm 0,19$ vezes maior do que o obtido para o controle (n $=4 ; \mathrm{P}<0,00001)$. Em contraste, nas culturas onde as concentrações de M-PHA excederam 10\%, tanto após quatro quanto cinco dias de cultivo, houve uma diminuição significativa do IP. Esse decréscimo de estímulo parece estar diretamente relacionado ao grau de toxidade da fitohemaglutinina, como anteriormente demonstrado com o teste de viabilidade com azul de tripano.

\section{Efeito de alcalóides sobre a imunomodulação de células mononucleares}

Quando se avaliou por CF os efeitos da vimblastina, um alcalóide de estrutura dímera isolado de C. roseus (vinca) como já citado, sobre a proliferação de células mononucleares na presença de fitohemaglutinina, nenhuma alteração foi observada nas concentrações de $10^{-10}$ e $10^{-9} \mathrm{M}$, com IP de 3,44 $\pm 0,41$ e 3,44 $\pm 0,34$ (n $=4$ ), respectivamente. Já nas concentrações superiores a $10^{-7} \mathrm{M}$, observou-se efeito tóxico. Entretanto, diminuição significativa da proliferação de MNC induzida por PHA na concentração de $10^{-8} \mathrm{M}$ foi observada (Figura 3.C), com um IP de somente $2,37 \pm 0,28$ em relação ao de $3,49 \pm 0,22$ obtido para a população tratada com $10 \%$ de M-PHA, sem a presença do alcalóide $(\mathrm{n}=3 ; \mathrm{P}=0,03)$. Interessante com relação a este efeito inibitório pontual da vimblastina é que ele assemelha-se ao efeito inibitório por ela apresentado na inibição da formação de microtúbulos descrito para trofozoítos da malária (Bell, 1998).

Em contraste, nos ensaios realizados com a vindolina, alcalóide isolado da mesma planta, mas de estrutura monomérica, não se observou efeito algum em nenhuma das concentrações avaliadas com relação à ativação ou à proliferação, independente da presença de mitógeno, pois a população inicial de linfócitos não sofreu o deslocamento esperado para essas células 
Tabela 1. Efeito de extratos preparados de diferentes plantas medicinais sobre a morfologia e a proliferação de células mononucleares humanas in vitro.

\begin{tabular}{|c|c|c|c|c|}
\hline \multirow{2}{*}{ EXTRATOS } & \multicolumn{4}{|c|}{ Blastos (\%) } \\
\hline & controle & $1 \mu \mathrm{g} / \mathrm{ml}$ & $10 \mu \mathrm{g} / \mathrm{ml}$ & $100 \mu \mathrm{g} / \mathrm{ml}$ \\
\hline C. recutita & \multirow{4}{*}{$5,8 \pm 1,2$} & $6,9 \pm 0,4$ & $6,8 \pm 0,3$ & $5,6 \pm 0,1$ \\
\hline B. microstachya & & $5,7 \pm 0,5$ & $3,9 \pm 0,5$ & $4,8 \pm 0,9$ \\
\hline H. lancifolius & & $10,5 \pm 2,1$ & $11,9 \pm 3,4$ & - \\
\hline fitohemaglutinina & & \multicolumn{3}{|c|}{$89,6 \pm 1,2$} \\
\hline & \multicolumn{4}{|c|}{ Índice de Proliferação } \\
\hline C. recutita & \multirow{4}{*}{1} & $1,00 \pm 0,03^{*}$ & $1,10 \pm 0,09$ & $1,35 \pm 0,03^{* *}$ \\
\hline B. microstachya & & $1,02 \pm 0,07$ & $1,63 \pm 0,11^{* *}$ & $1,44 \pm 0,08^{* *}$ \\
\hline H. lancifolius & & $0,91 \pm 0,27$ & $0,64 \pm 0,13^{*}$ & $0,07 \pm 0,02^{* *}$ \\
\hline fitohemaglutinina & & \multicolumn{3}{|c|}{$4,90 \pm 0,19$} \\
\hline
\end{tabular}

Suspensões de células mononucleares obtidas de sangue periférico de indivíduos sadios foram incubadas com as concentrações indicadas de extratos ou com meio de cultura contendo fitohemaglutinina $(10 \%)$ e incubadas a $37^{\circ} \mathrm{C}$, por 5 dias, em tensão de $\mathrm{CO}_{2}$. A morfologia foi avaliada em citocentrifugados corados com May-Grunwald-Giemsa, sob imersão em microscópio comum. Cada valor representa a percentagem média de blastos $\pm \mathrm{EPM}$, obtida de pelo menos três experimentos realizados em triplicata. Em paralelo, obteve-se o Índice de Proliferação por citometria defluxo, onde cada valor é o resultado da relação entre a média do número de eventos detectados nos testes pelo número obtido no controle. (* $\mathrm{P}<0,05 ; * * \mathrm{P}<0,01)$.

quando ativadas (Figura 5-D) e nem aumentou de número em relação às populações controle. Importante ressaltar que a viabilidade das células tratadas com vindolina, independente da presença de PHA, foi semelhante à apresentada pelos grupos controle, excluindo um efeito citotóxico para esse alcalóide.

Efeito de extratos de plantas medicinais sobre a imunomodulação de células mononucleares humanas

Estudos semelhantes realizados com concentrações crescentes de extratos preparados de capítulosflorais de C.recutita e de folhas de B. microstachya demonstraram ação estimulante significativa sobre a proliferação de células mononucleares humanas quando comparados ao grupo controle, porém muito inferior aos valores observados para as células tratadas com mitógeno na concentração de 10\% (Tabela 1). Em contraste, queda significativa do IP, proporcional à concentração, foi observada nos experimentos realizados com o extrato preparado de cascas de $H$. lancifolius. Ao avaliar-se essas células em citocentrifugados corados, a maioria estava representada por linfócitos, indicando que a fração majoritária desta população não foi ativada pela ação do extrato, refletindo provavelmente o baixo IP observado.

Ao investigar se os efeitos modestos resultantes poderiam ser decorrentes de toxidade dos extratos sobre os células mononucleares, observou-se que somente aquele preparado de folhas de H. lancifolius foi tóxico, com cerca de $65 \%$ de células viáveis na concentração de $10 \mathrm{ug} / \mathrm{mL}$, caindo para valores inferiores a $10 \%$ na concentração de $100 \mathrm{ug} / \mathrm{mL}$, confirmando que o extrato não possui atividade inibitória sobre a proliferação de linfócitos e, sim, que seu efeito é de natureza tóxica.

\section{DISCUSSÃO E CONCLUSÃO}

Linfócitos são as principais células responsáveis pela resposta imunológica adaptativa e o primeiro passo para sua ativação reside na interação de receptores presentes na superfície celular com um agente estimulante. Os eventos celulares que ocorrem após essa ativação são denominados coletivamente de transformação blástica e as células resultantes deste processo são referidas como células efetoras da resposta imunológica (Reeves; Todd, 2000). Bioquimicamente, o processo de ativação celular se caracteriza, dentre outros mecanismos, pelo recrutamento de íons cálcio e a ativação simultânea das enzimas tirosinaquinases citossólicas fosfolipase $\mathrm{C} \gamma$ e $\mathrm{A}_{2}$, proteína $\mathrm{C}$ quinase (PKC), proteína quinase ativada por mitógeno (MAPK) e calcineurina (Trama et al., 2000). Essas, por via de cascatas metabólicas específicas, produzem sinais direcionados ao núcleo, promovendo a transcrição de fatores pró-mitóticos. Esses, por sua vez, conduzem os eventos da proliferação e a síntese de IL2, a qual é o principal mediador químico da amplificação da 
resposta imunológica (Burgermeister et al., 2003, Feske et al., 2000).

Morfologicamente, linfócitos adquirem o fenótipo de linfoblastos após ativação e esta mudança fenotípica pode ser evidenciada por meio de preparados citológicos apropriadamente corados (Lee et al., 1999). Simultaneamente às alterações morfológicas após ativação, observa-se um aumento expressivo do número de células (Kristensen et al., 1982b), caracterizando a expansão clonal da população ativada, além da produção e secreção de citocinas, particularmente IL2, e da expressão de receptores específicos por essas células (Biberfeld, 1971).

Enquanto a resposta in vivo dos linfócitos a antígenos é específica, gerando amplificação clonal, sua resposta a mitógenos in vitro é inespecífica e influencia, simultaneamente, um grande número de células, levandoas a uma expansão policlonal. Diferente do que acontece in vivo, esse estímulo à proliferação não depende de células apresentadoras de antígenos, embora os mesmos mecanismos bioquímicos estejam aparentemente envolvidos (Burgermeister et al., 2003) e favorece estudos experimentais.

Muitas plantas têm sido utilizadas na medicina tradicional, não só pela sua eficiência em curar ou atenuar os efeitos da resposta imunológica, mas também pela facilidade de acesso e relativo baixo custo, uma vez que crescem naturalmente com relativa abundância em nosso solo. O desenvolvimento de técnicas in vitro de cultivo de linfócitos, além da aplicação prática, que se verifica em laboratórios de imunologia clínica, com o objetivo de diagnosticar a imunocompetência das células, tem, também, proporcionado ferramentas para elucidar os mecanismos que envolvem as respostas imunológicas, assim como para o estudo do efeito imunomodulador de várias substâncias.

Nesse trabalho, utilizou-se a CF como instrumento principal de avaliação da atividade imunomodulatória de células mononucleares humanas expostas à ação da fitohemaglutinina, por ser uma substância com reconhecida capacidade de estimular linfócitos $\mathrm{T}$ humanos in vitro. Por ser uma substância de relativa toxidade para essas células, uma série de experimentos usando concentrações crescentes do meio comercial denominado Meio de Cultivo para Cariótipo, o qual é rotineiramente usado para proliferação in vitro de células de sangue periférico e de medula óssea com finalidadesdiagnósticas porinduziraproliferaçãodecélulas sensíveis à fitohemaglutinina, foram realizados. Nesses ensaios, concentrações crescentes foram adicionadas a suspensões de MNC e seus efeitos sobre a transformação blástica e a proliferação monitorados por CF após cultivo sob diferentes condições. Os resultados demonstraram que a fitohemaglutinina é, de fato, ativadora e mitogênica para células mononucleares humanas quando cultivados a $37^{\circ} \mathrm{C}$, por cinco dias, em $10 \%$ de meio M-PHA sob tensão de $\mathrm{CO}_{2}$, pois cinéticas ideais para ambas atividades foram evidentes e confirmadas pela alteração morfológica das células. Além disso, a metodologia mostrou-se adequada para demonstrar sua ação extremamente tóxica em altas concentrações, corroborando com outros que relataram semelhante ação sobre linfócitos de sangue periférico de camundongos (Kristensen et al., 1982c) e de cachorros (Kristensen et al., 1982a).

Efeito oposto foi observado quando se incluiu, no sistema, vimblastina, confirmando ação semelhante já descrita (Jordan; Wilson, 2004, Thyberg et al., 1977, Wilson; Jordan, 2004). É importante ressaltar que esse alcalóide é freqüentemente utilizado em estudos in vitro de imunomodulação (Qin et al., 2002, Sciola et al., 2003, Yang et al., 1996) e que, à semelhança da colchicina, tem a capacidade de bloquear a mitose celular por inibir a polimerização da tubulina e, conseqüentemente, impedir a formação de microtúbulos indispensáveis ao fuso mitótico (Wilson; Jordan, 2004). Para a vindolina, a metodologia revelou ausência de atividade. Interessante ressaltar que a maioria das substâncias derivadas da vinca com atividade antimitótica possui estrutura dímera assimétrica variada e mudanças mínimas resultam em diferenças significativas não só com relação à toxidade, assim como às atividades anti-tumorais descritas (KirschVolders; Parry, 1996). Nesse contexto, a diversidade dos resultados aqui apresentados poderia, também, estar relacionada à estrutura química de cada alcalóide, visto que apenas os que possuem uma estrutura dímera têm atividade anti-neoplásica relatada.

Os resultados também demonstram que a metodologia foi sensível aos efeitos estimulantes dos extratos de $C$. recutita, em concordância com relatos anteriores usando diferente metodologia (Amirghofran et al., 2000), e de B. microstachya, pela primeira vez descrito. Entretanto, quando os efeitos inibitórios obtidos para o extrato de $H$. lancifolius foram investigados com maior profundidade, observou-se que os mesmos eram decorrentes de toxidade sobre o sistema, apontando para a importância de se usar técnicas complementares para a apreciação de efeitos biológicos causados por extratos de vegetais. Dessa forma, a citometria de fluxo mostrou ser um método de análise alternativo àqueles que utilizam reações enzimáticas ou a incorporação de elementos radioativos, confirmando relatos anteriores (Kristensen et al., 1982b, Wang; Zheng, 2002), e que pode ser útil quando se deseja investigar a ação de substâncias puras ou complexas como extratos de plantas, por exemplo, sobre a imunomodulação de células mononucleares humanas obtidos de sangue periférico.

\section{AGRADECIMENTOS}

Os autores agradecem a CAPES, CNPq e a Fundação Araucária/PR, pelo apoio financeiro a A.F. (CAPES), F.H.R. (PIBIC/CNPq), F.V.R.M. (PIBIC/ Fundação Araucária), e a C.A.M.S. (Bolsista CNPq - Brasil). 


\section{REFERÊNCIAS}

Amirghofran Z, Azadbakht M, Karimi MH 2000. Evaluation of the immunomodulatory effects of five herbal plants. $J$ Ethnopharmacol 72: 167-172.

Barbosa-Filho JM, Martins VKM, Rabelo LA, Moura MD, Silva MS, Cunha EVL, Souza MFV, Almeida RN, Medeiros IA 2006. Natural products inhibitors of the angiotensin converting enzyme (ACE). A review between 19802000. Rev Bras Farmacogn 16: 421-446.

Bell A 1998. Microtubule inhibitors as potential antimalarial agents. Parasitol Today 14: 234-40.

Bezerra-Santos CR, Peçanha LMT, Piuvezam MR 2005. Cissampelos sympodialis Eichl. (Menispermaceae) inhibits anaphylactic shock reaction in murine allergic model. Rev Bras Farmacogn 15: 287-291.

Biberfeld P 1971. Morphogenesis in blood lymphocytes stimulated with phytohaemagglutinin (PHA). A light and electron microscopic study. Acta Pathol Microbiol Scand [A] 223 Suppl: 221-270.

Brunner KT, Mauel J, Cerottini JC, Chapuis B 1968. Quantitative assay of the lytic action of immune lymphoid cells on 51-Cr-labelled allogeneic target cells in vitro; inhibition by isoantibody and by drugs. Immunology 14: 181-196.

Burgermeister E, Endl J, Scheuer WV 2003. Activation of cytosolic phospholipase A2 in human T-lymphocytes involves inhibitor-kappaB and mitogen-activated protein kinases. Eur J Pharmacol 466: 169-180.

Carlos IZ, Lopes FCM, Benzatti FP, Carli CBA, Marques MF, Jordão Junior CM, Rinaldo D, Calvo TR, Santos LC, Vilegas W 2005. Ação do extrato metanólico e etanólico de Davilla elliptica St. Hill. (Malpighiaceae) na resposta imune. Rev Bras Farmacogn 15: 44-50.

Civin CI, Loken MR 1987. Cell surface antigens on human marrow cells: dissection of hematopoietic development using monoclonal antibodies and multiparameter flow cytometry. Int J Cell Cloning 5: 267-288.

Duarte MR, Debur MC 2003. Caracteres morfo-anatômicos de folha e caule de Bauhinia microstachya (Raddy) J. F. Macbr (Fabaceae). Rev Bras Farmacogn 13: 7-15.

Farmacopéia Brasileira 1929. $1^{\text {a }}$ ed.

Farmacopéia Brasileira 1996. $4^{\mathrm{a}}$ ed. São Paulo: Atheneu.

Feske S, Draeger R, Peter HH, Eichmann K, Rao A 2000. The duration of nuclear residence of NFAT determines the pattern of cytokine expression in human SCID T cells. J Immunol 165: 297-305.

Funke I, Melzig MF 2006. Traditionally used plants in diabetes therapy - phytotherapeutics as inhibitors of $\alpha$-amylase activity. Rev Bras Farmacogn 16: 1-5.

Gaines H, Andersson L, Biberfeld G 1996. A new method for measuring lymphoproliferation at the single-cell level in whole blood cultures by flow cytometry. J Immunol Methods 195: 63-72.

Gillis S, Ferm MM, Ou W, Smith KA 1978. T cell growth factor: parameters of production and a quantitative microassay for activity. J Immunol 120: 2027-2032.

Hirazumi A, Furusawa E, Chou SC, Hokama Y 1996. Immunomodulation contributes to the anticancer activity of Morinda citrifolia (noni) fruit juice. Proc West Pharmacol Soc 39: 7-9.

Jordan MA, Wilson L 2004. Microtubules as a target for anticancer drugs. Nat Rev Cancer 4: 253-265.
Kirsch-Volders M, Parry EM 1996. Genetic toxicology of mitotic spindle inhibitors used as anticancer drugs. Mutat Res 355: 103-128.

Kristensen B, Kristensen F, Vandevelde M, Higgins RJ, de Weck AL 1982a. Canine lymphocyte cultures in vitro: evaluation of peripheral blood lymphocyte response to mitogens. Vet Immunol Immunopathol 3: 439-448.

Kristensen F, Walker C, Joncourt F, Bettens F, Weck AL 1982b. Human lymphocyte proliferation. I. Correlation between activated and proliferating T-lymphocytes. Immunol Lett 5: 59-63.

Kristensen F, Walker C, Muller J, Weck AL 1982c. Evaluation of murine thymocyte stimulation using a defined culture medium. Immunobiology 161: 429-441.

Lee GR, Foerster J, Lukens J, Paraskevas F, Greer JP, Rodgers GM 1999. Wintrobe's clinical hematology. (10th ed.). Philadelphia: Lippincott Williams \& Wilkins.

Leitão SG, Castro O, Fonseca EM, Julião LS, Tavares ES, Leo RRT, Vieira RC, Oliveira DR, Leitão GG, Martino V, Sulsen V, Barbosa YAG, Pinheiro DPG, Silva PEA, Teixeira DF, Lourenço MCS 2006. Screening of Central and South American plant extracts for antimycobacterial activity by the Alamar Blue test. Rev Bras Farmacogn 16: 6-11.

Lopes FCM, Placeres MP, Moreira RRD, Santos LE, Carlos IZ 2003. Avaliação da atividade imunológica de Achillea millefolium L. ("mil-folhas"). Rev Bras Farmacogn 13(Supl.2): 11-13.

Macey MG 1994. Flow cytometry - clinical applications. Oxford: Blackwell Scientific Publications.

Mosmann T 1983. Rapid colorimetric assay for cellular growth and survival: application to proliferation and cytotoxicity assays. J Immunol Methods 65: 55-63.

Nowell PC 1960. Phytohemagglutinin: an initiator of mitosis in cultures of normal human leukocytes. Cancer Res 20: 462-466.

Pereira RC, Oliveira MTR, Lemos GCS 2004. Plantas utilizadas como medicinais no município de Campos de Goytacazes - RJ. Rev Bras Farmacogn 14 (Supl. 1): 37-40.

Qin J, Tao D, Duan R, Leng Y, Shen M, Zhou H, Feng Y, Gao C, Yu Y, Li QQ, Hu J, Gong J 2002. Cytokinetic analysis of cell cycle and sub-phases in MOLT-4 cells by cyclin $\mathrm{E}+\mathrm{A} / \mathrm{DNA}$ multiparameter flow cytometry. Oncol Rep 9: 1041-1045.

Reeves G, Todd I 2000. Lectures notes on immunology. Oxford: Blackwell Science.

Robinson JP 1993. Handbook of flow cytometry methods. New York: Willey-Liss, Inc.

Sciola L, Spano A, Monaco G, Bottone MG, Barni S 2003. Different apoptotic responses and patterns in adhering and floating neoplastic cell cultures: effects of microtubule antagonists. Histochem Cell Biol 119: 77-90.

Shapiro HM 1985. Practical flow cytometry. New York: Alan R. Liss, Inc.

Thyberg J, Moskalewski S, Friberg U 1977. Effects of colchicine and vinblastine on the phytohaemagglutinin-induced transformation of lymphocytes. J Cell Sci 27: 183198.

Tôrres AR, Oliveira RAG, Diniz MFFM, Araújo EC 2005. Estudo sobre o uso de plantas medicinais em crianças hospitalizadas da cidade de João Pessoa: riscos e 
benefícios. Rev Bras Farmacogn 15: 373-380.

Trama J, Lu Q, Hawley RG, Ho SN 2000. The NFAT-related protein NFATL1 (TonEBP/NFAT5) is induced upon $T$ cell activation in a calcineurin-dependent manner. $J$ Immunol 165: 4884-4894.

Wang YY, Zheng XX 2002. A flow cytometry-based assay for quantitative analysis of cellular proliferation and cytotoxicity in vitro. J Immunol Methods 268: 179188.

Wilson L, Jordan MA 2004. New microtubule/tubulin-targeted anticancer drugs and novel chemotherapeutic strategies. J Chemother 16 Suppl 4: 83-85.

Yamaguchi H 1992. Immunomodulation by medicinal plants. Adv Exp Med Biol 319: 287-297.

Yang T, Buchan HL, Townsend KJ, Craig RW 1996. MCL-1, a member of the BLC-2 family, is induced rapidly in response to signals for cell differentiation or death, but not to signals for cell proliferation. J Cell Physiol 166: 523-536.

Zarkovic N, Vukovic T, Loncaric I, Miletic M, Zarkovic K, Borovic S, Cipak A, Sabolovic S, Konitzer M, Mang S 2001. An overview on anticancer activities of the Viscum album extract Isorel. Cancer Biother Radiopharm 16: 55-62. 